\title{
Across Regions: Are Most COVID-19 Deaths Above or Below Life Expectancy?
}

Rondy Malik ( $\nabla$ rjmalik@outlook.com )

Department of Ecology and Evolutionary Biology, The University of Kansas, Lawrence, KS, U.S.A. 66044

\section{Short report}

Keywords: Severe acute respiratory syndrome coronavirus 2 (SARS-CoV-2), coronavirus disease (COVID19), geographical and political landscapes

Posted Date: September 24th, 2020

DOl: https://doi.org/10.21203/rs.3.rs-80040/v1

License: (c) (i) This work is licensed under a Creative Commons Attribution 4.0 International License. Read Full License 


\section{Abstract}

Life expectancy varies across geographical and political landscapes for a multitude of reasons. Severe acute respiratory syndrome coronavirus 2 (SARS-CoV-2), the virus responsible for the 2020 coronavirus disease (COVID-19) and pandemic, is present in 215 countries, and is described as a pathogen that is most deadly to individuals 65 years and older. However, it is unclear if the majority of COVID-19-related deaths are targeting individuals above or below life expectancy. Through seven months of the 2020 COVID-19 pandemic, an association between life expectancy and COVID-19 related deaths were assessed. The reported age of those suffering from COVID-19-related death was evaluated across seven countries (United States, Germany, Hungary, Poland, South Africa, Sweden, and Switzerland), and placed into one of two categories depending on whether the death occurred above or below the country's life expectancy. Among the seven countries included in this survey, it was observed that there was greater proportion of deaths above life expectancy $(M=65.35 \%, S D=6.58)$ versus death below life expectancy $(\mathrm{M}=34.65 \%, \mathrm{SD}=6.58)$, and these difference were significant $(95 \% \mathrm{Cl}[18.51876,42.88199], p=0.0008349)$. Across countries, the disparity, or percent difference in deaths occurring above versus below life expectancy, was greatest in the countries with life expectancies of 80+ (Sweden, Switzerland, Germany). Given priorities that may need to be made in terms of hospital capacity, considering life expectancy may be an appropriate approach for reporting COVID-19-related deaths.

\section{Life Expectancy In The Age Of Covid-19}

Severe acute respiratory syndrome coronavirus 2 (SARS-CoV-2) is the cause of the 2020 coronavirus pandemic (COVID-19), which was first identified in Wuhan, China, and is now present in 215 countries (Cascella et al., 2020). Through economic hardship, estimated infection rate, health risk, and fatalities (Mandhana and Myo, 2020, Coro, 2020, Ogen, 2020); SARS-CoV-2 is responsible for a great deal of harm via the most recent global pandemic, and it has forced society to re-imagine life expectancy. Life expectancy is the expected age in which the average individual of a given population reaches before being deceased. While pandemics including bubonic plague, Spanish flu and the HIV/AIDS have long plagued the human population (McEvedy, 1988, Radusin, 2012, Control and Prevention, 2006), the recent COVID-19 pandemic features a novel coronavirus that is controversial because of its impact on older individuals, which may not have necessarily achieved life expectancy. In 1900, U.S. life expectancy was 48 years of age (United Nations, 2019), at the same time, infectious diseases such as influenza, mycobacterium tuberculosis, and enteritis-and diarrhea causing-parasites are thought to have caused $31 \%$ of all U.S. deaths - a century ago (Gorina et al., 2005). Since 1900, life expectancy has increased. Current life expectancies in South Africa, U.S., and Sweden; are $\sim 60, \sim 70$, and $\sim 80$, respectively.

To determine if COVID-19-related deaths are associated with life expectancy, deaths incidences above and below life expectancy were assessed across seven countries, and placed into binary categories (i.e 'deaths above life expectancy', and 'deaths below life expectancy'). While controlling for regional life expectancy, the aim of this survey was to uncover if the majority of COVID related deaths occur above or 
below life expectancy. It is hypothesized that disparity in those deaths occurring above and below life expectancy will vary across political borders.

\section{Assessing Reported Covid-19 Deaths: Above And Below Life Expectancy}

To determine if these deaths were occurring above or below life expectancy, data published by United States (Center for Disease Control), Germany (Robert Koch-Institut) , Hungary (Tájékoztató oldal a koronavírusról), Poland (Polityka Zdrowotna), South Africa (Institute for Communicable Diseases), Sweden (Folkhälsomyndigheten), and Switzerland (Bundesamt für Gesundheit) were used for this study. Data from these government agencies were downloaded from Statista (https://www.statista.com/). Since life expectancy is usually assessed in a manner specific to a particular region or country, incidence of death was categorized as above life expectancy or below life expectancy so that it was specific to each of the seven countries used in this study (Table 1). The percent of deaths occurring above or below life expectancy was recorded for each country. For each country, disparity (\% difference) was taken by calculating percent difference occurring above and below expectancy. Comparison between countries was necessary to account for regional differences that may impact death rate.

Analysis

Among the seven countries, 'all deaths above life expectancy' percentages $(n=7)$ were compared to their 'all deaths below life expectancy' percentages $(n=7)$. The Shapiro-Wilks test was employed to assess normality in distribution. In addition, Levene's test was used to assess equality in variance. A paired t-test is commonly used to determine difference in two variables from the same source. Here, proportionate deaths above and below life expectancy were compared from countries. In addition, Wilcoxon rank sign test, was also employed to verify the findings. The top three countries with the greatest disparity were compared against bottom four countries with lowest disparity using the Welch two sample t-test.

\section{Most Covid-19 Deaths Occur Above Life Expectancy}

The majority of COVID-19 deaths occurred above life expectancy (death above life expectancy, $M=65 \%$; versus death below life expectancy, $\mathrm{M}=35 \%$; Figure 1a, paired t-test, $95 \% \mathrm{Cl}[18.51876,42.88199], P=$ 0.0008349 ; Wilcoxon signed rank test, $p=0.0156$ ). Disparity was greatest in Switzerland, Sweden, and Germany (Figure 1b); showing that relative difference in deaths above life expectancy far exceeded deaths below life expectancy (Figure 1b). Interestingly, these same three countries have a life expectancy of 80 years or more.

South Africa, United States, Poland, and Hungary had more of a balance when considering deaths above versus below life expectancy. These four countries had disparities of less than $20 \%$ (Figure 1b), and were contrasted against countries with disparities of $20 \%$ or greater (Switzerland, Sweden, and Germany). Thus, an apriori contrast revealed significant differences between the two groupings (disparity above 
$20 \%, M=32.91 \%$; versus disparity below $20 \%, M=14.87 \%$; Welch Two Sample t-test, $95 \% \mathrm{Cl}_{[31.456656 \text {, }}$ $-4.573118] 2.54=-4.72, p=0.02566)$. The United States and South Africa were comparable in proportion of deaths below life expectancy (Figure 1c), but it is important to note that the United States has a life expectancy that outlasts South Africa by more than 10 years.

\section{Synthesis}

COVID-19 disproportionately harms older individuals. While this may be an accurate description, it does not consider the impact of the disease vis-à-vis life expectancy. The aim here was to assess how often these deaths occur above life expectancy. These findings reveal that $65 \%$ of COVID-19 deaths occur above life expectancy. COVID-19 differs from recent pandemics of the $21^{\text {st }}$ century because it disproportionately targets individuals over 65 year of age (D'Antiga, 2020). While bats are the reservoir host of SARS related coronaviruses, SARS-CoV-2 (i.e COVID-19) shares a $96 \%$ sequence identity when comparing humans and bats (Zhou et al., 2020). As SARS-CoV-2 disseminates throughout regions of the world, its genome will likely diversify (i.e founder effect), which may affect virulence and disproportionately impact specific age groups.

\section{Pandemics vary in targeted age class, but can they affect fitness?}

Viruses can disproportionately affect certain age classes. COVID-19 is most deadly among individuals 65 years and older (D'Antiga, 2020). This contrasts the 2009 H1N1 pandemic, which disproportionately targeted individuals below 65 years of age (Dawood et al., 2012). The recent Ebola pandemic, targeted individuals far below age 65. The average age of Ebola pandemic deaths was 32 years of age (Li et al., 2016). Depending on the pandemic, the window of opportunity to reproduce may be small, which may elevate Darwin's theory of natural selection (i.e survival of the fittest), which requires there to be an advantage/disadvantage toward reproduction. Infectious diseases that target individuals before they have had an opportunity to reproduce can reduce fitness. Average reproduction age varies across countries. In 1981, 20 percent of women in their early thirties were childless in the U.S. In 2016, this figure rose to about 30 percent (United States Bureau of the Census, 2020). Thus, the untimeliness of a pandemic or virulent virus (i.e Ebola) can disproportionately targets younger age classes (i.e $<40$ years of age) and may diminish fitness. As it relates to COVID-19, this virus targets individuals that are past peak age of reproduction, which may be indifferent to population fitness.

\section{Can variation in COVID-19 Deaths be explained by regional differences?}

Regional differences may also impact death rate. Countries in the northern hemisphere such as Sweden, Switzerland, Germany and the United States peaked in COVID-19 related deaths in April 2020, while in 
South Africa, COVID-19 related deaths peaked in late July 2020 (Tracking covid-19 excess deaths across countries, 2020). Environmental factors associated with a particular region may also be used to explain disparities in COVID-19 related deaths. Regions with high concentrations of $\mathrm{NO}_{2}$ corresponded to $78 \%$ of COVID-19 deaths (Ogen, 2020), and atmospheric $\mathrm{CO}_{2}$ was reported to be associated with infection rate (Coro, 2020). This may suggest that air quality may be a factor in deciding which populations are most at risk.

Different regions as well as variation in human hosts may also cause the virus to diversify according to a particular environment. SARs-CoV-2 may mutate and change according to characteristics of select regional hosts. Among humans, SARs-CoV-2 type $A$ and $C$ are mostly found in Europe and the Americas, meanwhile type B is most common to East Asia (Forster et al., 2020). Interestingly, it remains unclear which SARs-CoV-2 type is ancestral, and which two are derived (Mavian et al., 2020). This may be an important determinant as to how virus evolution may affect different regions.

Other factors explaining regional differences may include wealth and inequality. According to the GINI index, which measures wealth distribution; South Africa is one of the top 2 countries in wealth inequality, and the United States is in the top 40. All other countries used in this study was ranked between 126 and 152, according to the GINI index (CIA.gov, 2020 )

\section{Conclusion}

The impact of COVID-19 may differ across space and time. This survey suggests that approximately $65 \%$ of COVID-19 related deaths occurred above life expectancy. The difference in deaths above life expectancy versus below life expectancy was greatest in Switzerland, Sweden, and Germany. Considering life expectancy may be appropriate for governmental agencies targeting individuals most at risk to COVID-19, it is encouraged that life expectancy be taken into account when planning a response to localized COVID-19 outbreaks.

\section{Declarations}

\section{Ethical Approval and Consent to participate}

Not applicable

\section{Consent for publication}

Not applicable

\section{Availability of supporting data}

Public data was used for this article

\section{Competing interests}


Not applicable

\section{Funding}

Funding support provided by National Science Foundation Post-Doctoral Research Fellowship Biology Award \#1907242.

\section{Authors' contributions}

RJM conceived the idea, performed analysis, and wrote the manuscript

\section{Acknowledgement}

Special thanks and acknowledgement to Logan W. Cole for taking time to read and provide helpful comments regarding manuscript content. Special thanks to James D. Bever, D. Christopher Rogers and Dhaval Vyas for good discussions.

\section{References}

CIA.gov, 2020

Tracking covid-19 excess deaths across countries, 2020. The Economist.

United States Bureau of the Census, 2020.

CASCELLA, M., RAJNIK, M., CUOMO, A., DULEBOHN, S. C. \& DI NAPOLI, R. 2020. Features, evaluation and treatment coronavirus (COVID-19). Statpearls [internet]. StatPearls Publishing.

CONTROL, C. F. D. \& PREVENTION 2006. The Global HIV/AIDS pandemic, 2006. MMWR. Morbidity and mortality weekly report, 55, 841.

CORO, G. 2020. A global-scale ecological niche model to predict SARS-CoV-2 coronavirus infection rate. Ecological Modelling, 109187.

D'ANTIGA, L. 2020. Coronaviruses and immunosuppressed patients: the facts during the third epidemic. Liver Transplantation.

DAWOOD, F. S., IULIANO, A. D., REED, C., MELTZER, M. I., SHAY, D. K., CHENG, P.-Y., BANDARANAYAKE, D., BREIMAN, R. F., BROOKS, W. A. \& BUCHY, P. 2012. Estimated global mortality associated with the first 12 months of 2009 pandemic influenza A H1N1 virus circulation: a modelling study. The Lancet infectious diseases, 12, 687-695.

FORSTER, P., FORSTER, L., RENFREW, C. \& FORSTER, M. 2020. Phylogenetic network analysis of SARSCoV-2 genomes. Proceedings of the National Academy of Sciences, 117, 9241-9243. 
GORINA, Y., GOULDING, M. R., HOYERT, D. L. \& LENTZNER, H. R. 2005. Trends in causes of death among older persons in the United States.

LI, J., DUAN, H.-J., CHEN, H.-Y., JI, Y.-J., ZHANG, X., RONG, Y.-H., XU, Z., SUN, L.-J., ZHANG, J.-Y. \& LIU, L.-M. 2016. Age and Ebola viral load correlate with mortality and survival time in 288 Ebola virus disease patients. International Journal of Infectious Diseases, 42, 34-39.

MANDHANA, N. \& MYO, M. 2020. Pandemic Crushes Garment Industry, the Developing World's Path Out of Poverty. The Wall Street Journal.

MAVIAN, C., POND, S. K., MARINI, S., MAGALIS, B. R., VANDAMME, A.-M., DELLICOUR, S., SCARPINO, S. V., HOULDCROFT, C., VILLABONA-ARENAS, J. \& PAISIE, T. K. 2020. Sampling bias and incorrect rooting make phylogenetic network tracing of SARS-COV-2 infections unreliable. Proceedings of the National Academy of Sciences, 117, 12522-12523.

MCEVEDY, C. 1988. The bubonic plague. Scientific American, 258, 118-123.

OGEN, Y. 2020. Assessing nitrogen dioxide (NO2) levels as a contributing factor to the coronavirus (COVID-19) fatality rate. Science of The Total Environment, 138605.

RADUSIN, M. 2012. The Spanish flu, part II: The second and third wave. Vojnosanitetski pregled, 69, 917927.

UNITED NATIONS, P. D. 2019. World Population Prospects 2019.

ZHOU, P., YANG, X.-L., WANG, X.-G., HU, B., ZHANG, L., ZHANG, W., SI, H.-R., ZHU, Y., LI, B. \& HUANG, C.-L. 2020. A pneumonia outbreak associated with a new coronavirus of probable bat origin. nature, 579, 270273.

\section{Tables}

Table 1: Seven countries were assessed for this study. Life expectancies ranges are provided courtesy of World Bank - worldbank.org. Map was constructed using Maptive (www.maptive.com) 


\begin{tabular}{|l|c|}
\hline \multicolumn{1}{|c|}{ Nation } & Life Expectancy \\
\hline Sweden & $\sim 80$ \\
\hline Switzerland & $\sim 80$ \\
\hline Germany & $\sim 80$ \\
\hline Hungary & $\sim 75$ \\
\hline Poland & $\sim 75$ \\
\hline United States & $\sim 75$ \\
\hline South Africa & $\sim 60$ \\
\hline
\end{tabular}

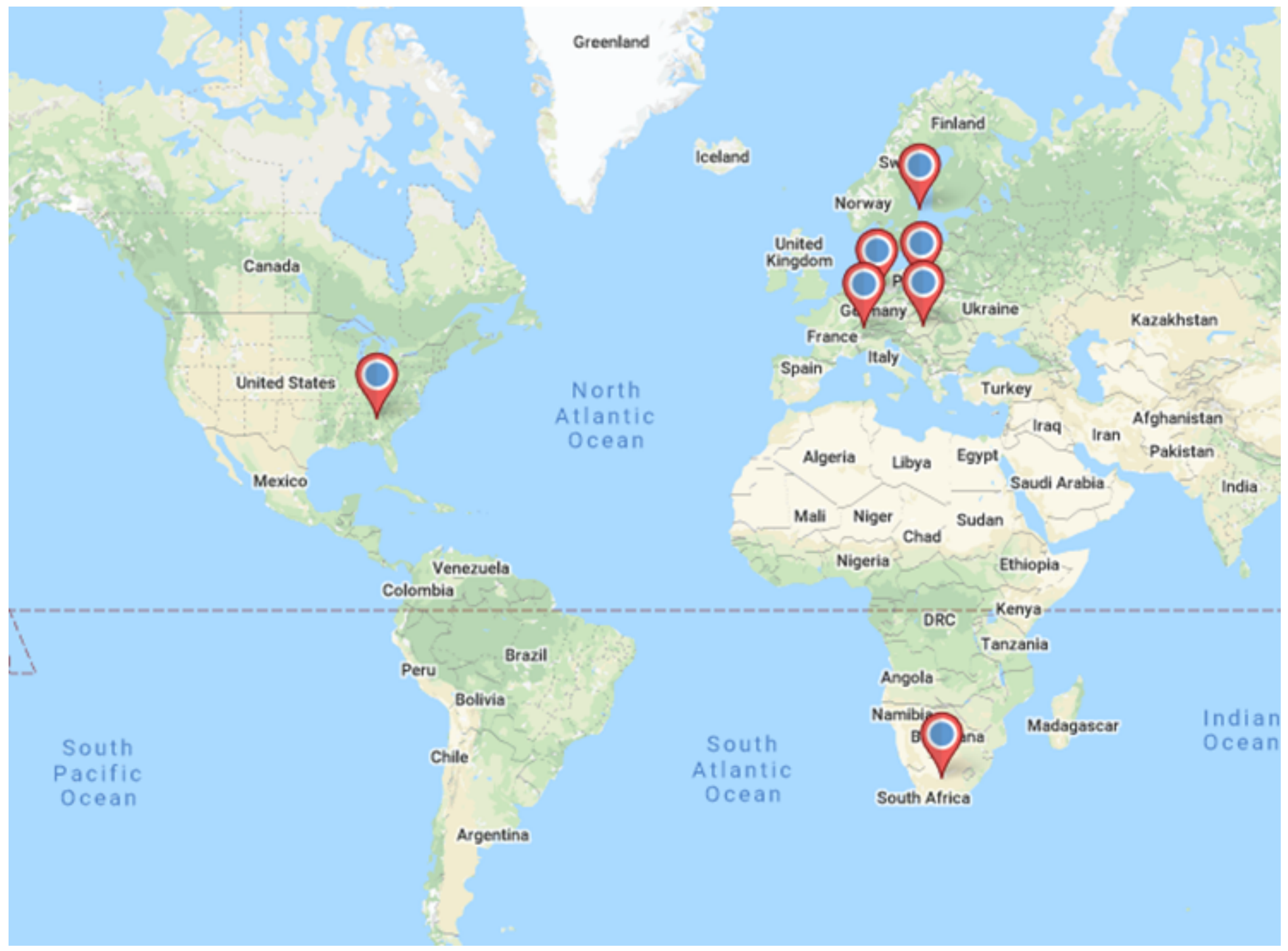

Figures 
b)
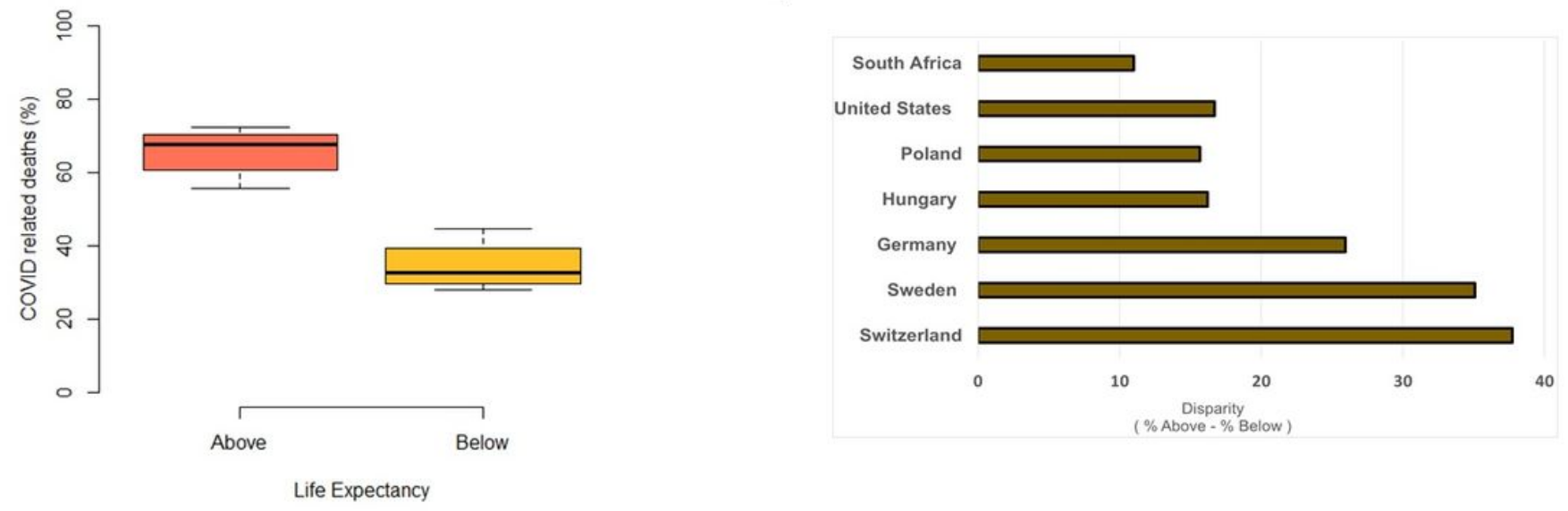

c)

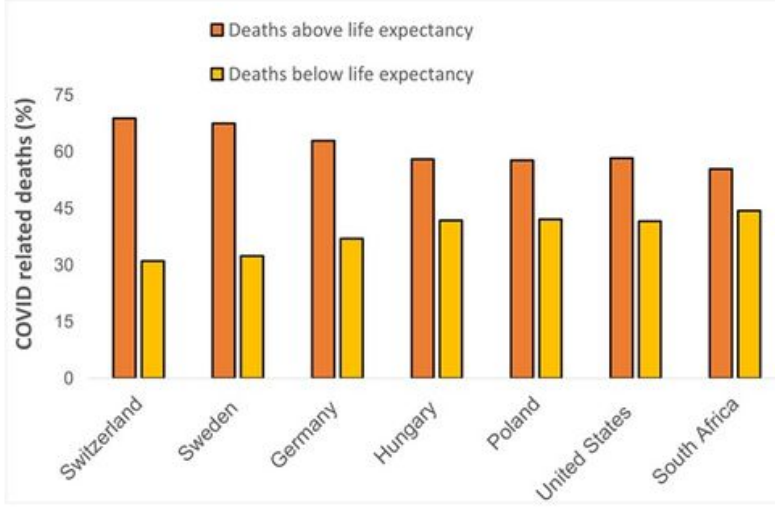

Figure 1

Life expectancy and COVID19-related death. A) Among countries, all deaths occurring above and below life expectancy were compared. B) Disparity, or relative difference in deaths above and below life expectancy. C) Above versus below life expectancy death across countries. 